\title{
Invited talk : Web Services Engineering
}

\author{
Mikio Aoyama \\ Nanzan University - Japan
}

\begin{abstract}
Web services are emerging platform on the Internet to reuse and integrate software as services across the organizational boundaries. However, few researches have been done on the methodologies for creating Web service applications. This article discusses the framework of Web Services Engineering to systematically develop Web service applications.
\end{abstract}

Key words: Web Services, e-Business, software development methodology, and software business model.

\section{INTRODUCTION}

Web services are emerging platform on the Internet to reuse and integrate software as services across the organizational boundaries [Aoya00, Benn00, Brer99]. A wide variety of technologies are developed for describing, publishing, looking up, and executing Web services. However, most of the technologies proposed so far focus on the platforms. Few researches have been done on the methodologies for creating Web service applications. Thus, we need to establish the framework for engineering Web service applications, namely Web Services Engineering [Aoya02b]. This article discusses the framework of Web Services Engineering.

The original version of this chapter was revised: The copyright line was incorrect. This has been corrected. The Erratum to this chapter is available at DOI: 10.1007/978-0-387-35614-3_21 


\section{SERVICE ENGINEERING AND WEB SERVICES}

\subsection{Abstraction of Web Services: Business-Service- Computing Model}

Web services are defined as "internet-based applications fulfilling a specific task or a set of tasks, that can be combined with other Web services to maintain workflow or business transactions" [IBM00]. One of the major goals of the Web services technologies is to separate the services from underlying computing platforms and make the services interoperable over the Internet. Thus, decentralization and interoperability are the essential aspects of Web services. To discuss the framework of Web Services Engineering, it's needed to clarify the abstraction of "Web services" and the relationship with other abstracts in applications. Thus, we proposed Business-Service-Computing Model as illustrated in Figure 1 [Aoya02a]. The model comprises the following three layers of abstracts:

1) Computing space comprises conventional programs and software components running on the computing platforms. This layer deals with the implementation of services.

2) Service space represents the Web services and their relationships. Unlike general meaning of "services", we assume all the Web services are executable on computers.

3) Business space comprises business entities and their relationships. Some business entities may not be executed by computers.

By separating the concerns into the three layers, the application development is decomposed into two successive mappings: from business space to service space, then to computing space. 


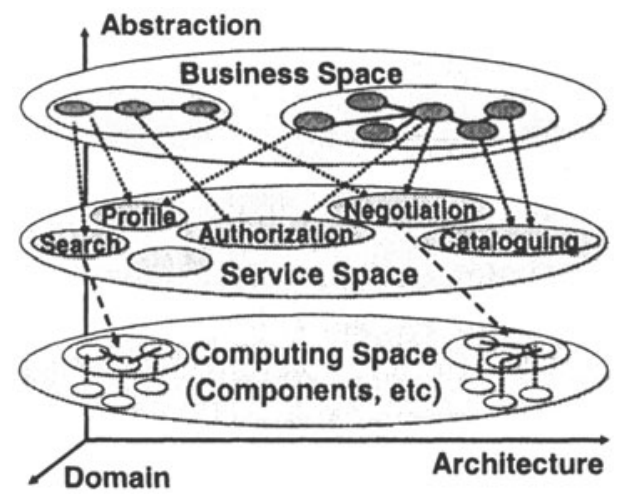

Figure 1 : Business-Service-Computing Model

\subsection{Scope and Dynamics of Web Services}

Another major aspect of Web services is the extension of the scope of applications. Applications in the 90s embraced the concept of "enterprise". ERP (Enterprise Resource Planning) is the typical enterprise application. However, the major advantage of the Web services come from the interoperability across the enterprises. Applications such as SCM (Supply Chain management) and CRM (Customer Relationship Management) are focusing on the relationship between organizations and/or people, and optimize whole process between one end to another. Here, we have identified three collaboration patterns as illustrated in Figure 2.

1) Collaboration within enterprise like EAI (Enterprise Application Integration).

2) Closed/static collaboration across the enterprises within a group of trusted enterprises.

3) Open collaboration among the enterprises. Examples include trading on marketplace and auction. 


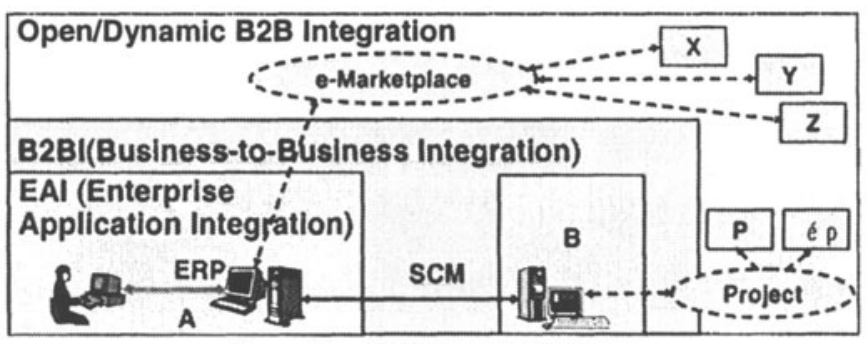

Figure 2: Collaboration Patterns

\section{DEVELOPMENT METHODOLOGY OF WEB SERVICES}

\subsection{A Framework of Methodology}

Although the goal of a Web service application is basically the same to conventional application, it's a challenge to take advantage of the service abstracts in order to develop Web service applications more efficiently.

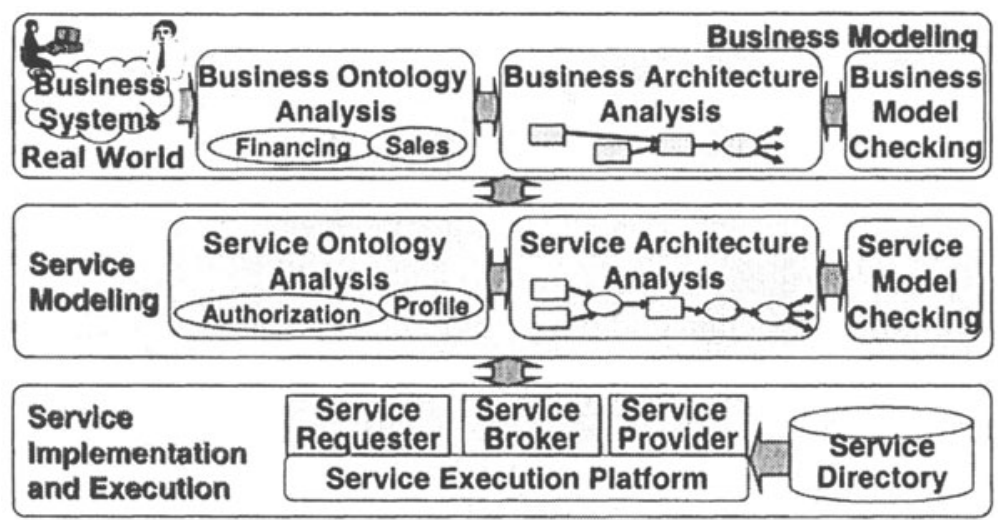

Figure 3 : Framework of Web Services Development Methodology

Based on the Business-Service-Computing Model, we are developing the service-oriented development methodology for creating Web service applications.

As illustrated in Figure 3, the methodology consists of three processes, business modelling, service modelling and service implementation and 
execution, which correspond to business space, service space and computing space.

\subsection{Business-Driven Service Creation Methodology}

To model the collaboration across the enterprises is the key issue to develop Web service applications. Such model is called "choreography". There are two views to model the collaborations:

1) Flow model, such as work flow model, represents the collaborative process between the enterprises. To represent the process in an organization and across the organizations, private workflow and public workflow are distinguished. Workflowbased Web services modelling languages, such as WSFL (Web Services Flow Language) [Laym01] and ebXML BPSS (Business Process Specification Schema) [BPSS01], have been proposed.

2) Field model, such as collaboration model, represents the interaction between the enterprises.

Figure 4 illustrates a field-based model to describe collaboration among enterprises, such as trading over the Internet [Aoya02a]. The model emphasizes the dynamic change of behaviour of the actors by dynamically binding roles to the actors.

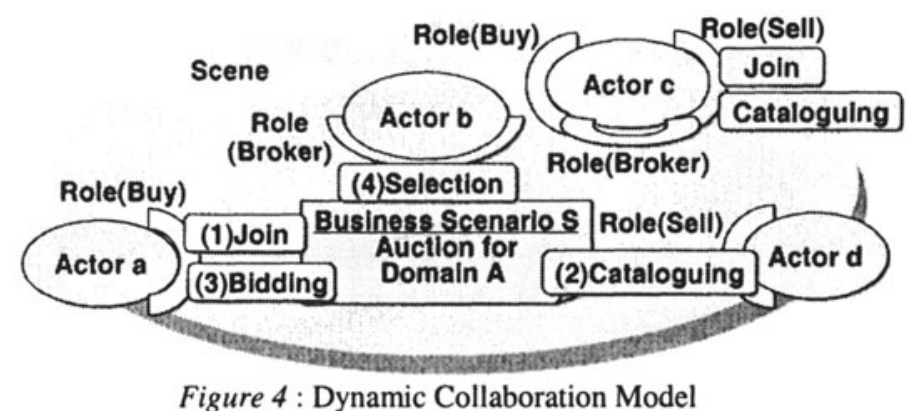

The model is based on theory of drama and consists of the following entities:

a) Actor: An active entity

b) Role: Played by an Actor in a Scene

c) Service: Task performed by an Actor with a Role

d) Scene: Context of plays of Actors

e) Scenario: A sequence of plays in a Scenario 


\section{A PILOT PROJECT}

As a part of five-year government project, we are developing the prototype applications of Web services for "digital manufacturing" [AIST01]. The applications intend to provide computer-aided functions, including $\mathrm{CAD}, \mathrm{CAM}$ and $\mathrm{CAE}$, as services over the Internet.

\section{FUTURE STUDIES}

As illustrated in Figure 5, we are witnessing the emergence of new model of software business; software as services.

One business model is ASP (Application Service Provider), which is intended to lease expensive software packages, such as ERP. Variations of ASP are called XSP.

Another model is Web services which enable to reuse arbitrary software over the Internet. By lease/rental model, users do not need to own the software. Thus, Web services change the way we use software and software business model. Furthermore, service directory such as UDDI (Universal Description, Discovery and Integration) [UDDI00] is expected to have big impact on both technology and business by providing high level directory services. We expect Web services technologies will enrich software business portfolio as illustrated in Figure 5.

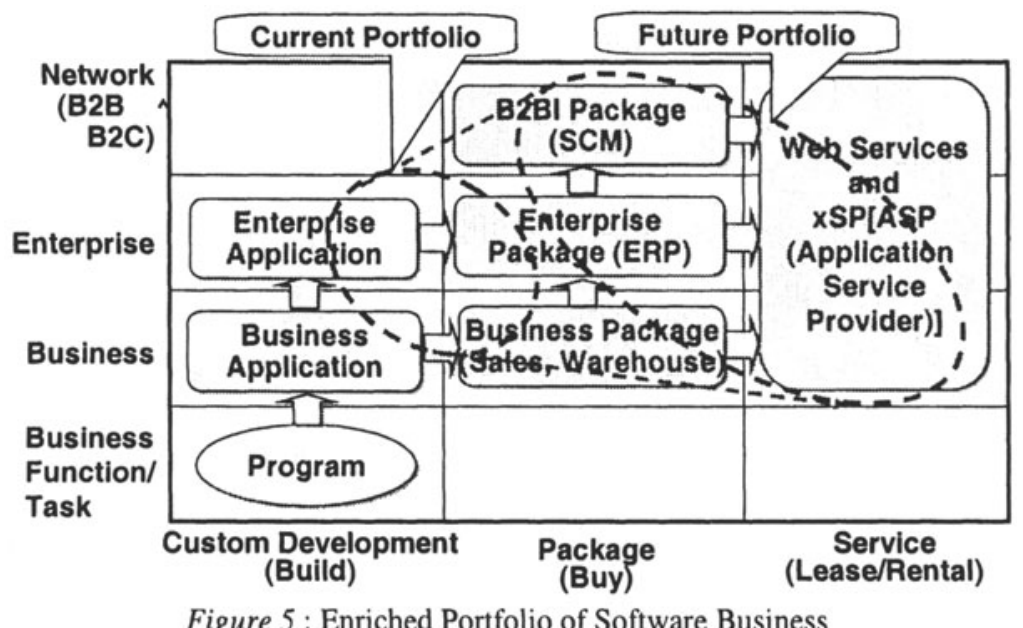

Figure 5 : Enriched Portfolio of Software Business 
The impact of Web services is even expected to go far beyond software business; to whole businesses [Hage01].

\section{CONCLUSIONS}

This article briefly discusses the framework of Web Services Engineering. Although big impact of Web services technologies is expected, big challenges are also foreseen. As our daily life is depending more and more on the Internet, the importance of the Web services is ever increasing. Much more research efforts are needed.

\section{REFERENCES}

[AIST01] http://unit.aist.go.jp/digital-mfg/.

[Aoya00] M. Aoyama, Intelligent Software Services over the Internet, Information Modeling and Knowledge Bases, IX, IOS Press, The Netherlands, Feb. 2000, pp. 128-135.

[Aoya02a] M. Aoyama, A Business-Driven Web Service Creation Methodology, M. Aoyama, H. Maruyama, and S. Weerawarana, (eds.), Proc. WebSE (Int'l Workshop on Web Services Engineering) 2002, IEEE CS Press, Nara, Jan. 2002, pp. 225-228.

[Aoya02b] M. Aoyama, et al., Web Services Engineering: Promises and Challenges, Proc 24th ICSE, May 2002, Orlando, pp. 647-648.

[Benn00] K. Bennett, et al., Service-Based Software: The Future for Flexible Software, Proc. APSEC 2000, IEEE CS Press, Singapore, Dec. 2000, pp. 214-221.

[Bich01] M. Bichler, The Future of e-Markets, Cambridge University Press, 2001.

[Brer99] P. Brereton, et al., The Future of Software, CACM, Vol. 42, No. 21, Dec. 1999 , pp. $78-84$.

[BPSS01] ebXML Business Process Project Team, ebXML Business Process Specification Schema, v. 1.0.1, May 2001, http://www.ebxml.org/specs/ebBPSS.pdf. 
[IBM00] IBM, Web Services: Taking e-business to the Next Level, White Paper, 2000, http://www-3.ibm.com/services/uddi/papers/e-businessj.pdf.

[Hage01] J. Hagel III and J. S. Brown, Your Next IT Strategy, Harvard Business Review, Oct. 2001.

[Leym01] F. Leymann, Web Service Flow Language (WSFL1.0), May 2001, http://www-4.ibm.com/software/solutions/webservices/pdf/WPS.pdf.

[UDDI00] UDDI, UDDI V1 Technical White Paper, Sep. 2000, http://www.uddi.org. 